\title{
Guidance and Regulation of College Students' Network Public Opinion from the Perspective of Law
}

\author{
Zheng Lin \\ School of Mathematics and Statistics \\ Zaozhuang University \\ Shandong, Zaozhuang 277100
}

\begin{abstract}
College students' network public opinion objectively reflects their ideology and is one of the important indicators for observing and studying college students today. The ideological and political education workers in colleges and universities should make it a priority to research on college students' network public opinion currently. The collection, management and treatment of college students' network public opinion is a systematic project that needs to be planned in long term and has key research orientation. From the perspective of law, through the correct guidance and regulation of the network public opinion, colleges and universities can effectively promote the benign function of the opinion. College students can also gain cognitive and judgmental abilities, and schools can improve their management level and college students can grow in a better environment.
\end{abstract}

Keywords-network public opinion; college students; legal guidance; legal regulation

With the popularization of network in recent years, the number of netizens in China has been increasing year by year. By December 2017, the number of Internet users in China had reached 772 million, increasing 40.74 million. And the Internet usage rate had reached $55.8 \%$. [1] It shows that as the internet information proliferates, most people, especially today's college students, have gotten closer to the Internet. The Internet society and the real society get deeply integrated, and the network has gradually become the mainstream media of college students, and the carrier of network public opinion. The network public opinion of college students, that is, the interpretation and remarks made by college students on real life issues in Internet communication, has a certain thought tendency, which reflects the common attitude and reaction of college students to specific events. In view of the fact that the importance of network public opinion is comparable to the touchstone of social stability, it is urgent and important to for us study network public opinion.

This article is the result of the 2016 Shandong Humanities and Social Sciences Research Program (Ideological and Political Education Research) (No. J16YB58).

\section{The Status Quo and Problems of College} Students' InTERNET PuBlic OPINION FROM THE PERSPECTIVE OF LAW

\section{A. Legal consciousness and non-legal consciousness coexist}

The current Chinese society is in the process of transforming from traditional society to modern society, during which the legal consciousness and non-legal consciousness coexist among college students. However, the establishment of legal consciousness by college students is an important factor in realizing the rule of law. At the Fourth Plenary Session of the 18th CPC Central Committee, Comrade Xi Jinping emphasized the need to rule the country by law, enhance people's view of government by law, and promote the construction of a society ruled by law. In the traditional concept, Confucianism and Legalism have Patriarchal hierarchy, with morality outweighing law. Whereas the modern rule of law requires university students to establish human rights protection, legal supremacy, and legal thinking. [2] Judging from college students' network public opinion, some college students can use legal thinking on problems, which reflects the modernization of law thinking. However, some college students still retain the traditional ethics that are incompatible with modern society. These traditional ideas need to be transformed into modern rule of law and law thinking.

\section{B. Undergraduates have insufficient respect and trust in the} law

From the network public opinions of many judicial cases, the law has not established enough authority among undergraduates. In 2015, two undergraduates from Henan robbed birds' nests, which arouse comprehensive online attention. They illegally purchased and caught precious and endangered species of wildlife, sentenced to fixed-term imprisonment of 10 and a half and 10 years respectively and fined [3]. Once the case was reported, it caused a firestorm online. The result could hardly resonate with the public, especially with undergraduates. They thought that, robbing birds' nests and selling 16 precious birds can be sentenced to fixed-term imprisonment of not less than 10 years, while the corruptions amounting to tens of millions or even billions of Yuan ended up that way too. As ordinary citizens, they all have 
certain awareness of the law, but not all of them master in it. Therefore, we can only set up the reverence and trust of the law through every specific precedent. However, the result like this surprised the public. Undergraduates failed to accept it, which may cause them lacking awe and confidence in the law. In fact, according to the Article 341(1) of the Criminal Law of the People's Republic of China, "the especially serious circumstances" are those who catch 10 second-class protected wildlife, and they shall be sentenced to fixed-term imprisonment of not less than ten years and shall also be fined or be sentenced to confiscation of property. Thus, in this case, the court made proper judgment, but the media should objectively report it and the netizen should calmly regard it. Otherwise, this great opportunity to popularize the Animal Protection Act and prefect the law would turn into the outlet for the public to express their feelings [4]. The meaning of the law, except for punishing criminals, is to popularize the legal education to the public, especially to the undergraduates who are going to integrate into the society.

\section{No law on network public opinion guidance and regulation in place.}

The network public opinion has both positive and negative influence on government management. China has kept on strengthening the monitoring and management of network public opinion. Laws and regulations related to network public opinion are gradually increasing, covering many aspects of political, economic, cultural, and social life. However, with the rapid development of the Internet, the network has almost connected all Internet users, especially the large amount of college students. In the face of the network public opinion caused by social events, the existing laws and regulations can no longer comprehensively work out, as the law usually lags and the current laws and regulations on network public opinion are not perfect or systemic enough. [5] There are dozens of legal norms concerning network management, but the low legislative level results in low legal validity. In cases involving network public opinion, when these norms confront other higher-level laws, they may be abandoned, resulting in an embarrassing situation where no law can be followed. Therefore, it is necessary to complement the existing network public opinion laws and regulations, and maintain the sound development of the network from the legislative level.

\section{Legal Guidance and Legal Regulation of College STUDENTS' NETWORK PuBliC OPINION}

\section{A. Legal guidance on college students' network public opinion}

1) Guide college students to enhance their legal awareness and strengthen the concept of the legal system

The college students have their own representative way of thinking and language characteristics, and the Internet as a kind of open media without borders but freedom, various values, ideologies and cultural forms coexist. Due to the lack of legal awareness and the ability to distinguish between right and wrong, some college students are interested in some Western anti-China forces' resistance to socialist ideology, and even echo hostile forces. They do not know that their behavior and language are not harmful to national stability and social harmony and unwittingly violate the bottom line of the law. [6] This has a lot to do with the fact that many students only focus on professional knowledge on the campus, while neglect the legal concept and the legal awareness. When participating in major social events and social hotspots, college students will involve the political, economic, and cultural aspects of the country, and will involve the moral and legal aspects. Therefore, we should carry out the law education for college students, teach Constitution, Civil Law, Criminal Law, Administrative Law, Law of the PRC on Public Security Administration, Tort Law of China, Marriage Law and other laws through the publicity video and various forms, such as mock courts and legal cases, to enhance their legal knowledge. That will help college students know and understand the law when participating in network public opinion, and they can abide by the law themselves in the process. [7] Strengthening the law education of college students is an effective way to prevent college students from breaking the law in participating in network public opinion. It can enhance the legal awareness and legal concept of college students, and can also improve the comprehensive quality of college students.

2) Establishing college students' network public opinion management institutions to effectively guide the public opinion direction

To establish a network public opinion guidance mechanism, we can set up a network public opinion management institution for college students, to timely observe their opinions, and effectively guide college students in network public opinion with strict manner and self-discipline. [8] Establishing the institution is the basic way to master college students' network public opinion, and it is also an effective system to guarantee the implementation of college students' network public opinion guidance mechanism. To complete that, a special department can be set up within the education system to cooperate with the network public opinion management institutions of the government. And encourage various industries involving network management to cooperate with the supervision of the university network public opinion management institutions. The guiding work of college students' network public opinion management institutions mainly includes the following aspects: (1) supervising the network public opinion of college students, mastering the trends and contents of their opinion; (2) promptly publishing the development and processing of network public opinion to college students to let them have an objective, comprehensive and accurate understanding of network public opinion; (3) establish a network answering system to solve the questions of college students in network public opinion.

\section{B. Legal Regulation of College Students' NetworkPublic Opinion}

At present, there are few provisions legislated on network public opinion in China. It is possible to introduce law that regulate network opinion at appropriate times, referred to as network public opinion law, and improve China's laws and regulations on network public opinion management. The following aspects should be studied in detail. 
1) Full implementation of the limited real name system with the real name in the background and net name in the foreground

Participating in these online discussions with net names, people would lack responsibility and moral awareness, due to the virtual and secret network. They may even ignore the bottom line of the law and be irrational and emotional while expressing themselves. Thus, in terms of the online supervision, the law regulates that we shall use real-name registration system in backstage. It has two advantages: one is that the system could efficiently reduce online criminal acts [9]. Real identification is used when one registers net name, which would let him aware that his words and deeds are subject to the law and social morality. Therefore, one will express himself obeying the law and social morality and reduce the probability of defamation, personal attack and other malicious acts. The other is that a person can only register once with valid identity information on an online communication platform. That could efficiently avoid internet water army and pushing hands from registering dozens even hundreds of accounts and using them to sway the public's opinion and trigger the social conflicts.

\section{2) Legalize the network spokesperson system}

The network spokesperson system is a kind of network administrative system of the government. The spokesperson of the government will release the social events undertaken by the department or the network events highly concerned by the public on the network in a timely, accurate and authoritative manner, and respond to public consultations and questions on the internet. It is a new way for government departments and the public to participate in network public opinion and interact effectively. Through the law, the network spokesperson system is legalized and promoted, which has the following advantages.

(1) Participate in events in advance and increase the controllability of network events. Timely collect network public opinion and the orientation, and stop the spread of rumors by official declare. Unveil the one-sided speech and false rumors in the network in real time, guiding the network public opinion to develop in the right direction as much as possible. A good public opinion environment prevents the deviation of network public opinion and provides solutions.

(2) Establish government authority and enhance the government's credibility. Because this new method is more timely and relevant than others, it can improve the accuracy of government departments to understand public opinion and the speed of information processing, which is conducive to fostering the diligent and practical work style of government officials. Promote the effective functioning of government and maintain a responsible and efficient government image. [10]

(3) Establish a new channel for public participating in politics. The network spokesperson system can effectively guarantee people's rights to know, participate, express, and supervise, thus becoming an important platform for the public to appeal, and a new window for government departments to understand the public's demands.

\section{3) Establish a network public opinion information grading} system

As the network information is confusing, it is necessary to establish a specialized network public opinion information grading system through which we can deal with the opinion according to the classification and level. Authorize different departments to collect and supervise information, and timely obtain corresponding information to make judgments and response in the first place, so as to more effectively regulate the network public opinion [11]. The establishment of a network public opinion information grading system has the following advantages. It can let the public know the boundaries of free speech and legally voice themselves, and effectively supervise bad opinion to the maximum extent, so that illegal speech cannot be spread. To establish the grading mechanism, we can draw on the 'Emergency Response Law of the People's Republic of China” and determine the grading of network public opinion based on factors such as the urgency, the development and the degree of harm that may be caused. The grading system includes three levels. The network public opinion involving national security and political stability is characterized in the first level (significant). Those involving the people's livelihood such as social fairness and justice, the distribution system, major government activities are in the second level (moderate). The emergencies related to public health and safety and property security are in the third level (mild). Accurately determining the classification of network public opinion depends on two key factors. One is quantitative analysis that is collecting useful information from network public opinion. The other is qualitative analysis with which we can quickly determine the nature and importance of network public opinion [12]. In a word, establishing a network public opinion information grading system is important for coping with the public opinion crisis faced by college students and maintaining social stability.

As for the network public opinion by college students, we do not control their content, but to guide and regulate the direction with a series of legal means. Deliver correct information to college students, and resolve the contradictions and crises of network public opinion. Prevent the deterioration of network public opinion. All these measures are contribute to helping students form the concept and habits of going online in a civilized manner, and promoting the process of democratic politics and the democratization of social management.

\section{REFERENCES}

[1] According to the statistics of China Internet Network Information Center (CNNIC). The 41st Statistical Report on Internet Development in China, 2018(1).

[2] Zhang Wenxian. A Study of Xi Jinping's Rule of Law (Part II)-The Core Viewpoint of Xi Jinping's Comprehensive Rule by Law [J]. Law and Social Development, 2016,(4).

[3] Wu Qingshu, Chen Liuqing. Multidimensional Perspective of Controversy Caused by "Heavy Sentence for Birding Catching in Henan Province” [J].Rule of Law, 2016,(02).

[4] Wu Junbin. Onthe Agreement, Limitation and Path of Network Negotiation Democracy [J].Studies on Marxism, 2015,(03).

[5] Fang Jinyou.On the Path of Network Public Opinion Management in the Period of Social Transformation[J].Academics,2013,(7). 
[6] Zhou Weihua, Xu Fabo.Introduction to Network Public Opinion[M]. China Renmin University Press, 2016:01.

[7] Wang Yanhong. On the Countermeasures of College Students' Moral Misconduct in the Network Public Opinion [J]. Social Sciences Journal of Universities in Shanxi, 2012,(11).

[8] Tang Yayang, Li Yabin. Retrospect and Prospect of University Network Public Opin ion Research [J]. Journal of Social Science of Hunan Normal University, 2013,(2).
[9] Guan Jianwen. Annual Report on China's Mobile Internet Development (2016)[M]. Social Sciences Academic Press(CHINA),2016:06.

[10] Yin Jianguo. On Government Governance Mechanism of Network Information in China[J]. China Legal Science, 2015,(01)

[11] Tang Huixi. Research on the Legal System of Government Supervision of Network Information [M]. Wuhan University Press, 2015:01.

[12] Interpretation and Practical Guide to the Emergency Response Law of the People's Republic of China [M]. China Democracy and Law Press, 2014:02. 